\title{
Barriers to Technology Use in Large and Small School Districts
}

\author{
Gregory M. Francom \\ Northern State University, Aberdeen, SD, USA
}

\author{
gregory.francom@northern.edu
}

\begin{abstract}
Barriers to effective technology integration come in several different categories, including access to technology tools and resources, technology training and support, administrative support, time to plan and prepare for technology integration, and beliefs about the importance and usefulness of technology tools and resources. This study used survey research to compare reported barriers to technology use in smaller school districts and communities to those in larger school districts and communities. This study also sought to determine other district and classroom factors that could influence barriers to technology integration. The population for this study was current public K12 teachers in a rural North Midwestern state. Findings indicated that teachers in smaller districts and communities reported more access to technology tools and resources and higher administrative support for the use of technology than did teachers in larger districts and communities. By contrast, teachers in larger districts and communities reported higher time to plan and prepare for technology integration.
\end{abstract}

Keywords: technology integration, barriers, school district, rural, access, training, time, beliefs

\section{Introduction}

Technology continues to be a mainstay in U.S. K-12 public education institutions, and researchers, and administrators have long advocated the integration of technological tools and resources into learning activities. However the promise of technology for transforming the educational enterprise has not been fully realized because of a variety of barriers to technology integration that are identified in the literature (Cuban, 2009; Ertmer, 1999; Ertmer, Ottenbreit-Leftwich, Sadik, Sendurur, \& Sendurur, 2012). These barriers have been classified in various ways.

One way to classify such barriers to technology use is to create a distinction between first-order and second-order barriers (Ertmer, 1999; Ertmer et al., 2012). First-order barriers to technology use include those barriers that are external to the teacher, including resources, training and sup-

(CC BY-NC 4.0) This article is licensed to you under a Creative Commons AttributionNonCommercial 4.0 International License. When you copy and redistribute this paper in full or in part, you need to provide proper attribution to it to ensure that others can later locate this work (and to ensure that others do not accuse you of plagiarism). You may (and we encourage you to) adapt, remix, transform, and build upon the material for any non-commercial purposes. This license does not permit you to use this material for commercial purposes. port, while second-order barriers include those barriers that are internal to the teacher, including personal confidence, beliefs about learning, and beliefs about the importance of technology for learning (Ertmer, 1999).

Over time, more specific categories of barriers (both first-order and second-order) have been identified in the literature. These categories of barriers include access to technology tools and resources, technology training and support, administrative support, time to plan and prepare for technology 
integration, and beliefs about the importance and usefulness of technology tools and resources (Hew \& Brush, 2007; Inan \& Lowther, 2010; Kopcha, 2012; Reinhart, Thomas, \& Toriskie, 2011; Ritzhaupt, Dawson, \& Cavanaugh, 2012). These barriers continue to affect teachers' technology integration efforts in K-12 public education; however, there is a paucity of research on the different types of settings in which certain barriers are manifest. Existing research on this issue does not often provide a clear picture of the different types of settings in which different barriers exist, nor does it indicate how barriers might be different for teachers in various school districts and communities.

The purpose of this study is to investigate the existence of barriers to technology integration in K12 public schools in a North Midwestern state and to compare larger and smaller school districts on barriers to technology integration. This study can enhance our understanding of teachers' use of information technologies in different K-12 public educational settings. Findings from this study can also help us predict the types of barriers to technology use that teachers are likely to encounter based on the size of the school district, community or other district and classroom factors, and also provide guidance on removing barriers to technology use in education.

\section{Literature Review}

Possible barriers to effective technology integration come in several different categories including access to technology tools and resources, technology training and support, administrative support, time to plan and prepare for technology integration, and beliefs about the importance and usefulness of technology tools and resources (Hew \& Brush, 2007; Inan \& Lowther, 2010; Kopcha, 2012; Reinhart et al., 2011; Ritzhaupt et al., 2012).

Ertmer et al. (2012) suggest that first-order barriers to technology integration have been decreasing as teachers continue to gain more and more access to technological tools and resources in schools. This has increased focus on the importance of other barrier categories such as time to plan and prepare for technology integration, and beliefs about the usefulness and importance of technology for learning (Ertmer \& Ottenbreit-Leftwich, 2010). However, other reports indicate that a lack of time to plan and prepare for technology integration continues to be one of the most frequently reported barriers in the literature (Dawson, 2008; Kale \& Goh, 2014; Lyons, 2007). Studies also indicate that a lack of access to technology tools and resources may continue to be a significant barrier (Kale \& Goh, 2014; Wright \& Wilson, 2011), especially in more rural districts and communities (Howley, Wood, \& Hough, 2011).

Some important practices and suggestions for schools to use to overcome barriers to technology integration have included situated professional development and mentoring (Kopcha, 2012; Ruggiero \& Mong, 2015; Wright \& Wilson, 2011), providing quality technology support (Inan \& Lowther, 2010), allowing high access to technological tools and resources (Clark, 2006), and allowing adequate time for instructors to plan for technology integration (Hew \& Brush, 2007). There are also teacher (second-order) factors deemed important to overcome barriers to technology integration, including increasing personal readiness or ability to use and integrate technology (Inan \& Lowther, 2010; Sang, Valcke, Braak, \& Tondeur, 2010) and developing positive beliefs about the importance and usefulness of technology (Holden \& Rada, 2011; Ruggiero \& Mong, 2015).

The barriers to technology use in K-12 education are well known and documented in the literature. However, a gap in the literature includes how these barriers are different for teachers in different types of districts and communities, particularly smaller, more rural communities. An exception to this includes a study by Lewis (2010) focusing on barriers to technology use by rural K-12 teachers. This study suggests that rural teachers need relevant technology training, adequate time to plan for technology integration, and better access to technology support (Lewis, 2010). 
However, this study does not indicate which barriers to technology use are more significant in rural settings than they are in suburban or urban settings.

Another study by Howley et al. (2011) compares teacher attitudes in smaller more rural communities and school districts to those in larger, more urban communities and school districts. This study found more positive attitudes about technology integration among rural teachers than it did among non-rural teachers; however, the study also indicated that rural teachers continue to have limited access to educational technologies (Howley et al., 2011).

The study by Howley et al. (2011) compares rural versus non-rural school districts on teacher beliefs as they relate to technology use for learning and access to technology, but does not provide an overall picture of the full range of barriers to technology integration and how they differ in rural versus non-rural schools. The current study builds upon the idea of comparing rural versus non-rural school districts, but is more comprehensive in its approach. It uses survey research to compare the full range of known barriers to technology use among different types of school districts and classrooms, especially among districts of different sizes and in different-sized communities.

\section{Purpose and Research Questions}

The purpose of this mixed-methods survey research study was to determine current barriers to technology integration and compare these barriers in different-sized school districts and communities. The research questions for this study include the following:

- What barriers to technology use are present in K-12 public education classrooms, and are there differences in these barriers among larger vs. smaller school districts?

- What other district and classroom factors are present that could influence barriers to technology integration in K-12 public education classrooms?

This study uses primarily quantitative methods (survey), with a minor qualitative component (follow-up interviews), to address these questions.

\section{Methods}

\section{Participants and Setting}

A survey and follow up interviews were conducted with participants from K-12 public education institutions in a rural North Midwestern state in the United States. Study participants included only current public K-12 teachers. To solicit responses, an email with a link to the survey was sent to 12,161 school district employees. A total of 1,185 participants completed the survey. After removing respondents who did not consent to the study or who did not currently work as a teacher, the total number of valid respondents was $\mathrm{N}=1079$.

Within the survey, participants were asked if they were willing to participate in a follow-up interview asking more in-depth questions about barriers to their technology use in the K-12 classroom and other aspects of their classroom practice. Though this study is primarily quantitative, a small number of interview participants $(\mathrm{N}=11)$ were purposefully selected from the pool of willing respondents to shed light on quantitative survey results. This small number of interview participants was selected to allow in-depth responses to a small list of selected questions without reaching data/theme saturation (Creswell, 2006; Mills \& Gay, 2016). These participants were purposefully selected to provide perspectives from various different school districts, grades, and subjects. They came from elementary, middle school, and high school levels and represented a range from small 
(101-300 students) to large (more than 3,000 students) school districts and communities (300-600 people to more than 50,000 people).

\section{Instruments}

A quantitative educational technology survey was developed by the researcher that collects information in four main areas including demographic information, technologies in the classroom, barriers and factors that relate to technology integration, and student-centered uses of technology. The survey development was informed by previous literature on elements of student-centered learning with technology (An \& Reigeluth, 2012; Reigeluth, Beatty, \& Myers, 2016; Reigeluth \& Karnopp, 2013) and barriers to technology integration (Ertmer, 1999; Hew \& Brush, 2007; Kopcha, 2012; Ritzhaupt et al., 2012). Survey items for this study were based on previous valid surveys implemented by Kopcha (2012) and Ritzhaupt et al. (2012) to study technology integration.

The completed educational technology survey included 48 questions. Several of these questions included demographic information, such as current work responsibility, age, school district and school size, number of people in the school's community, and subject and grade area taught. Information about technology tools available in the classroom was gathered using eight questions. Nine questions asked about student-centered technology integration in the classroom, and 18 questions asked about barriers to technology integration. These 18 questions were organized into the five main categories of barriers, including access to technology tools and resources, technology training and support, administrative support, time to plan and prepare for technology integration, and beliefs about the importance and usefulness of technology tools and resources (see Hew \& Brush, 2007; Kopcha, 2012; Reinhart et al., 2011; Ritzhaupt et al., 2012). Some sample survey items include, "At my school, I have access to the best educational technologies," "When I have a problem with a technological tool or resource, I receive quick and effective assistance," and "I have enough time to plan and prepare lessons that use technology." Participants responded to these questions with likert-scale responses indicating the amount of agreement they have to the items.

The qualitative interview question protocol, which was used later in the study, included four sections, each with a small number of questions. These sections included demographics, available technologies, technology use, and barriers to technology use. This protocol was designed to provide further information about participants' survey responses.

\section{Procedures}

A pilot test of the survey was administered to four teachers within the population. These teachers offered several different suggestions to help improve the survey responses, which were used to improve the survey before it was sent out. Email addresses for teachers in the population were gathered by checking the website for each of the 150 school districts in the state. If email addresses were not provided on the website but a faculty list was provided, then email addresses were generated from the faculty list. A few districts had no email or faculty listing and thus had to be excluded from the potential sample population. At the end of this process, a total of 12,161 school district employees' email addresses were collected. This number of email addresses was close to the number of full time teachers reported to be working within the state at the time of the study.

When institutional IRB approval was obtained for this study, emails soliciting participation were sent out to all of the 12,161 collected email addresses. Three emails were sent to each available participant with about a week's time in between each sending. At first sending, the researcher received feedback that some school district networks blocked access to the survey at the link provided. The second and third emails provided an alternative link which could be accessed by a 
wider variety of school district personnel. Out of the 12,161 addressees, 1,079 completed the survey and provided valid responses.

Interviews were conducted several months after the survey data were analyzed. The interview participants were interviewed over the phone and recordings of the interviews were transcribed for qualitative content analysis.

\section{Data Analysis}

Survey response data $(\mathrm{N}=1079)$ were coded with number values and each question was analyzed for descriptive statistics. Groups of questions within each of the five categories of barriers were tallied up for average scores for each respondent. Statistical analyses on these average scores were calculated using general linear model univariate ANOVA calculations. A significance level of $\mathrm{p}=.05$ was applied throughout.

For the barriers section of the survey, a deeper look into the different factors revealed Cronbach's Alpha calculations of $\alpha=.560$ for questions about access to technology tools and resources, $\alpha=$ .672 for questions about administrative support, $\alpha=.789$ for questions about technology training and support, $\alpha=.711$ for questions about time to plan and prepare for technology integration, and $\alpha=.638$ for questions about beliefs about the importance and usefulness of technology tools and resources. Since some of these items are below the desired $\alpha=.7$ reliability measure, results from this survey about technology access, administrative support and beliefs within the barriers section are presented using descriptive statistics and/or with some caution. However, a calculation of reliability for the entire barriers section of the survey was a reliable $\alpha=.792$.

For the purpose of comparing large vs. small districts, district size information was simplified to large and small. Large districts were defined as those of more than 1,500 students and small districts were defined as those with 1,500 or fewer students. The reason for this designation is that about half of the responses came from each of these groups. Also, community size data was simplified in a similar manner with communities of more than 5,000 comprising larger communities and communities of up to 5,000 people designated as smaller communities. About half of the responses came from each of these two community size groups.

Follow-up interviews with participants were recorded and transcribed. The interview responses from all participants were combined into a single document and organized by question. The responses were further organized to separate participants in larger school districts and communities from participants in smaller school districts and communities. The interview responses were analyzed for content and themes which were then connected to earlier quantitative findings from the survey.

\section{Results}

\section{Demographics}

127 of $150(84.6 \%)$ of all public school districts in the state were represented in this study. Respondents included teachers of every grade (K-12) and also covered a wide variety of subject areas, from K-5 grades to different subjects in middle and high school. School districts from fewer than 100 students to more than 3,000 students were represented in this study. The majority of respondents reported coming from a school district of more than 3,000 students (34\%), however the next largest group of respondents reported coming from a school district of 101-300 students (about 23\%). Respondents also reported coming from a variety of school sizes, and the most common school sizes were 101-200 students (17.8\%), 401-500 students (about 13\%) and more than 1,000 students $(12.9 \%)$. 
Respondents reported average class sizes ranging from fewer than 10 to more than 50 students. About $34 \%$ of respondents reported average class sizes of $21-25$ students, which was the most common response, with and 16-20 students as the next most common response (22\%). Respondents reported working in schools within communities ranging from fewer than 300 people to more than 50,000 people in population. About $23 \%$ reported working in a school in a community of more than 50,000 people, the most common response on the survey.

As for years of teaching experience, respondents ranged all the way from 1-4 years up to more than 40 years. The most common response was $21-30$ years experience $(22.4 \%)$ with $1-4$ years of experience as the second most common response $(20.8 \%)$.

\section{Overall Barriers to Technology Integration}

The first research question for this study asks about barriers that are present in K-12 public education classrooms. The survey featured several questions in five categories, including access to technology tools and resources, technology training and support, administrative support, time to plan and prepare for technology integration, and beliefs about the importance and usefulness of technology tools and resources. The highest percentage of respondents reported agreement with questions within the category on the beliefs on technology usefulness and difficulty $(85.95 \%$ of respondents agreed). This means that respondents believe that technology is useful and important for learning and that it is possible to find new learning resources (see Figure 1). This suggests that negative teacher beliefs about the importance and usefulness of technology tools and resources is not a significant barrier to technology use.

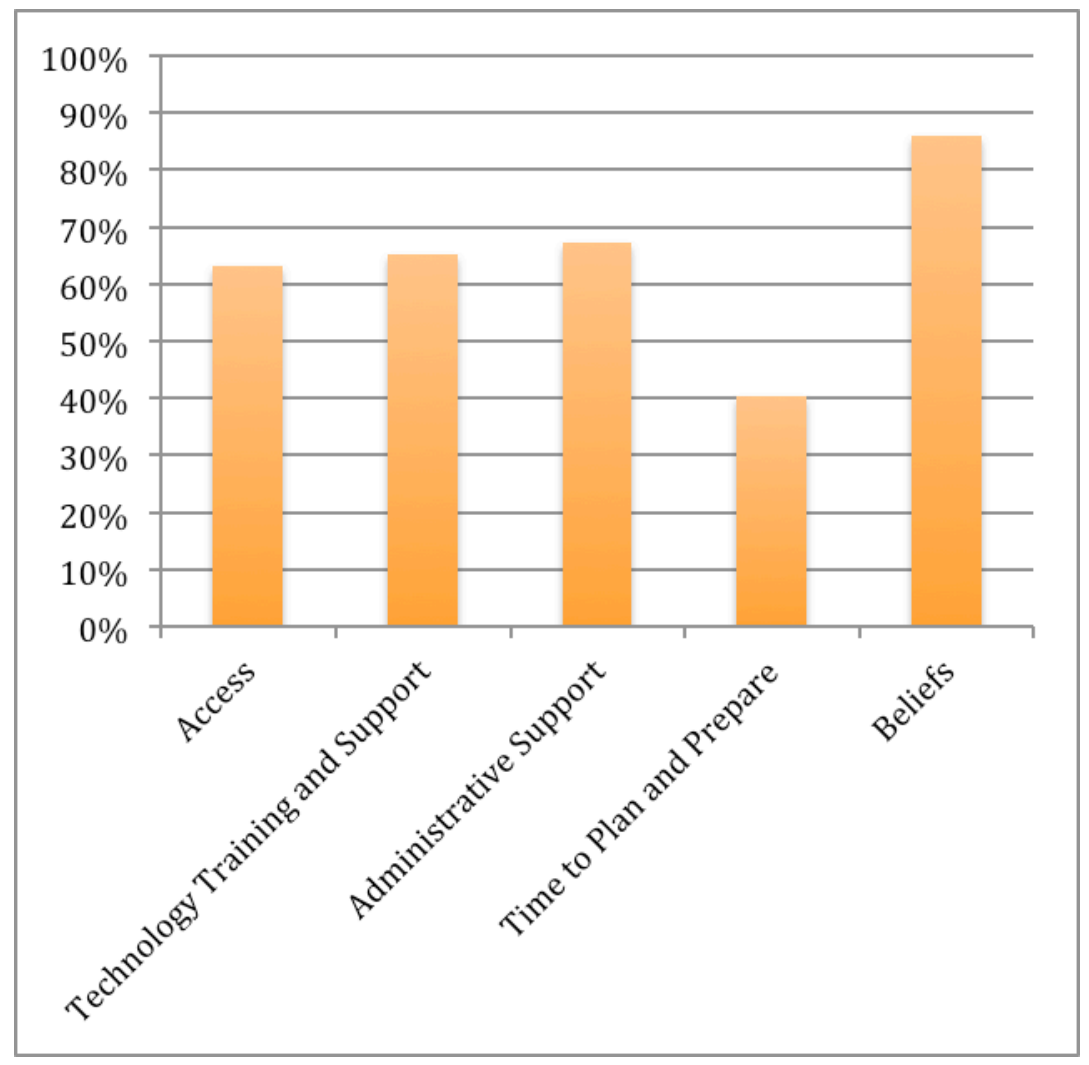

Figure 1. Percentage of agreement for responses within the five barrier categories. A higher percentage of agreement means that the item is less of a barrier to technology use.

In the administrative support category of the survey, questions were asked about administrative desire for teachers to integrate technology into learning, and the possibility of incorporating new 
technologies and learning methods into teaching and learning activities without prior permission. This was the next highest category for agreement (67.38\%), meaning that $67.38 \%$ of respondents felt that administrative support for technology integration was high and therefore not a significant barrier to technology use.

$65.10 \%$ of respondents agreed with items in the technology training and support category. Agreement in this category indicates that respondents felt that the training they receive is adequate and connects well to classroom practice, and that they receive quick and effective assistance for technology problems. This was the third least significant barrier to educational technology use in the classroom.

The most significant barriers to technology use in the classroom were a lack of access to technology $(63.05 \%$ agreement $)$ and a lack of time to plan and prepare for technology integration (40.48\% agreement). A lack of time to plan and prepare for technology integration was by far the most significant barrier to technology use present in K-12 public education classrooms. Questions in this survey category simply asked whether respondents felt like they had adequate time to plan and prepare for technology integration.

Questions in the access to technology portion of the survey asked about whether respondents and their students had access to the latest technologies, social media sites, and other resources for learning. Responses indicate that many teachers felt they didn't have adequate access to technology to allow for successful technology integration.

\section{School District and Community Size as Factors}

The first research question in this study also asks whether there are differences in barriers to technology use between larger and smaller school districts. Further statistical analysis revealed that district size was a factor in which barriers were reported. Respondents from smaller (1,500 students or fewer) school districts reported statistically significantly higher responses in the access to technology tools and resources category $[\mathrm{F}(1,1046)=6.483, \mathrm{p}=.011]$, and the administrative support category $[\mathrm{F}(1,1046)=22.733, \mathrm{p}<.001]$. Similar findings emerged when statistical analyses were run on community size. Respondents that work in school districts within smaller (up to 5,000 people) communities were significantly more likely to report better access to technological tools and resources $[\mathrm{F}(1,1060)=12.369, \mathrm{p}<.001]$ and better administrative support $[\mathrm{F}(1$, $1058)=35.103, \mathrm{p}<.001]$ than those in larger (more than 5,000 people) communities (see Figure 2 ). This suggests that a lack of access to technology tools and resources is a more significant barrier in larger communities and districts than it is in smaller communities and school districts. Also, administrative support for the use of technology in the classroom is reported to be higher in smaller communities and districts than it is in larger communities and school districts.

Survey respondents from larger school districts (more than 1,500 students) reported statistically significantly higher responses in the time to plan and prepare for technology integration category $[\mathrm{F}(1,1045)=6.008, \mathrm{p}=.014]$, as did respondents from larger communities (more that 5,000 people) $[\mathrm{F}(1,1054)=3.859, \mathrm{p}=.050]$. This suggests that within smaller school districts and communities, a lack of time to plan and prepare for technology integration is a more significant barrier than it is in larger school districts and communities.

There were no significant differences found between larger and smaller school districts on the technology training and support $[\mathrm{F}(1,1045)=.175, \mathrm{p}=.676]$ and beliefs about the importance and usefulness of technology tools and resources $[F(1,1045)=1.146, p=.285]$ categories. Nor was community size a significant factor in any of these two barrier categories. 


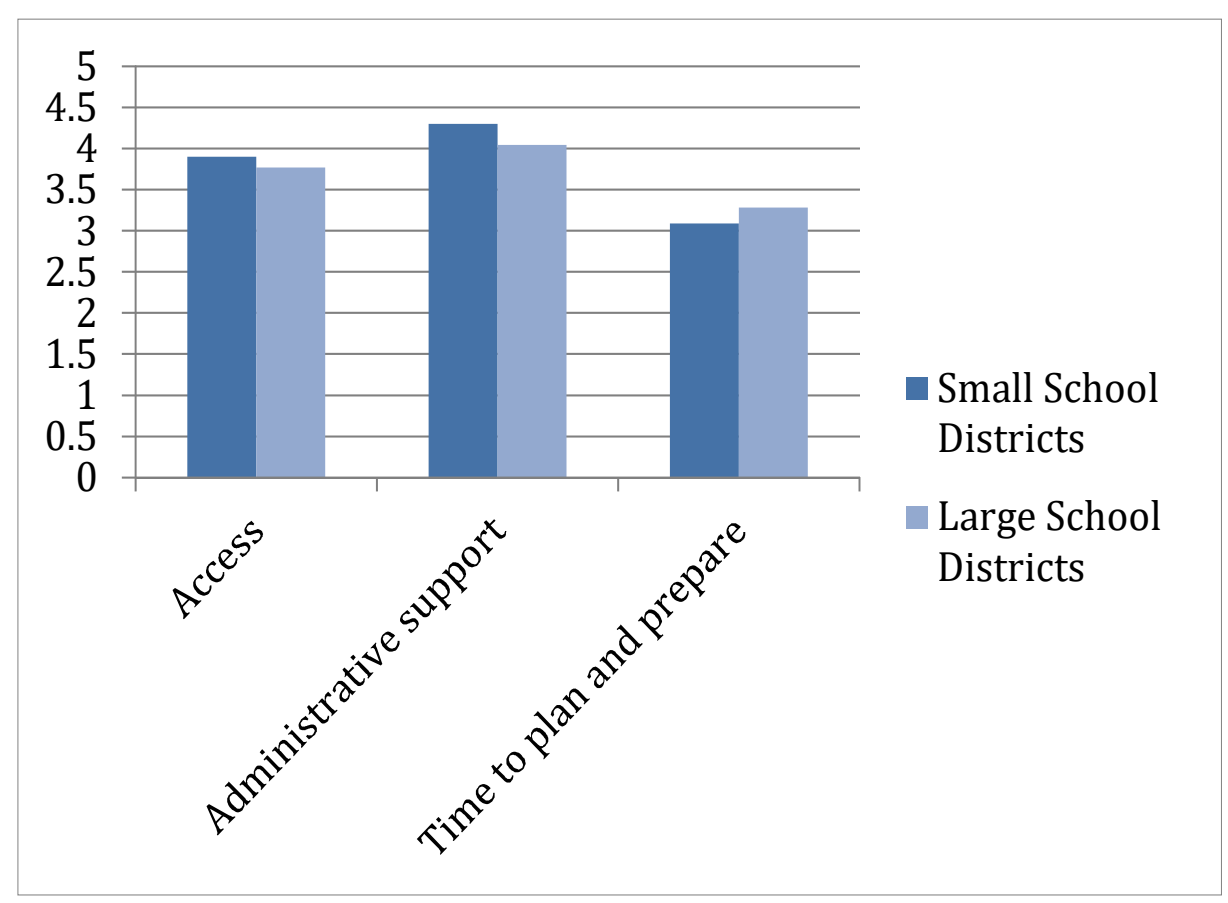

Figure 2. Mean scores for access, administrative support and time to plan and prepare in large and small school districts. A higher score means that the item is perceived to be less of a barrier to technology integration.

\section{Other Factors Related to Barriers}

The second research question in this study asks about other factors that could influence barriers to technology integration in K-12 public education classrooms. Further analysis of such possible factors including age, class size, number of students at the school, grade level, community size, and years of teaching experience were tested. Findings indicate that age was a significant factor on whether respondents were likely to report a lack of time to plan and prepare for technology integration category $[\mathrm{F}(5,1062)=5.885, \mathrm{p}<.001]$. Post Hoc comparisons indicate that respondents in their 20's are more likely to indicate that they have sufficient time to plan and prepare lessons that integrate technology than do those in their 40's or 50's. Respondents in their 30's are also significantly more likely to indicate that they have sufficient time to plan and prepare for technology integration than those in their 40's. Age was not found to be a factor for any other categories in the survey for barriers to technology use.

Class size was also a factor for the reporting of some of the barriers to technology integration. Respondents with class sizes of 20 students or fewer students were significantly more likely to report higher administrative support for technology integration than respondents with 21 or more students in class $[\mathrm{F}(2,1066)=7.157, \mathrm{p}=.001]$. Respondents with class sizes of 16-20 students were also significantly more likely to report better access to technological tools and resources than were respondents with class sizes of $26-30$ students $[F(10,1063)=3.048, p=.001]$. Post Hoc tests revealed no significant differences between other class size groups in the data. Class size was not a factor in any of the other barrier categories. 


\section{Discussion}

Previous research has indicated the types of barriers to technology use in education that may exist, but has not often indicated how these barriers are different for teachers in different types of districts and communities. There is also a paucity of research indicating what barriers to technology use are more significant in smaller more rural school districts and what barriers are more significant in larger school districts.

Categories of barriers to technology use in this study, listed from most significant to least significant overall are (a) time to plan and prepare for technology integration, (b) access to technology tools and resources, (c) technology training and support, (d) administrative support, and (e) beliefs about the importance and usefulness of technology tools and resources. Each of these categories will be discussed in order, in relation to the research questions, interview findings, and previous research.

\section{Time to Plan and Prepare for Technology Integration}

The most cited barrier in this study was time to plan and prepare for technology integration, a finding consistent with other research reports on barriers to technology integration (Bauer \& Kenton, 2005; Dawson, 2008; Kale \& Goh, 2014; Lyons, 2007). The first research question in this study asks about differences between barriers to technology use among larger and smaller school districts and communities. This study shows that respondents from larger, more suburban school districts were more likely to report having sufficient time to plan and prepare for technology integration than were respondents from smaller, more rural school districts. This finding is in line with a previous study that advocated providing rural teachers with more time to plan and prepare for technology integration (Lewis, 2010).

Follow-up interview responses indicate that few teachers - whether from small districts and communities or large ones - feel that they have sufficient time to plan and prepare for technology integration. One respondent from a small district and community shared, "Either we do [planning for technology integration] at home during weekends, or coming early, or leave late during the school day, so we feel that we don't have enough time to do that." Respondents from larger districts and communities also shared this sentiment. One respondent emphatically declared, "There is never enough time. I don't care what kind of a teacher you are, there is never enough time."

In addition, this study adds to the previous literature with findings that younger respondents (in their 20's and 30's) are more likely to report having sufficient time to plan and prepare technology lessons than those in their 40's and 50's. In interview responses, two respondents in their 40's and 50's mentioned having significant issues as they learn about and plan lessons with new technologies. By contrast, two respondents in their 20's and 30's discussed learning and incorporating new technologies as a fairly straightforward process, "I scrape by usually yes. I have five classes so I'm pretty busy, but I feel like for the most part the technology doesn't take very long." Another younger respondent shared, "I think that when you're first using something that new, it's a little more challenging to find time to try and incorporate something that you haven't used before, but once you get past that kind of stage then I think that we have a pretty good amount of time." Previous studies suggesting that younger teachers have a higher comfort and familiarity with technology tools and resources (see Inan \& Lowther, 2010; O’Bannon \& Thomas, 2014) may explain the finding that these younger teachers are more likely to report having sufficient time to plan and prepare for technology integration.

\section{Access to Technology Tools and Resources}

A first-order barrier to technology integration - lack of access to technological tools and resources - was the second most significant barrier cited in this study. This suggests that first-order 
barriers to technology integration, which are hypothesized to be decreasing over time (Ertmer et al., 2012), may continue to be a significant obstacle to technology integration (Kale \& Goh, 2014; Wright \& Wilson, 2011).

The first research question in this study asks about differences between barriers to technology use among larger and smaller school districts and communities. Respondents from smaller, more rural school districts reported higher access to technological tools and resources than did respondents from larger, more suburban school districts. This original finding goes against previous hints in the literature that rural school districts have access to fewer technological tools and resources (e.g., Howley et al., 2011; Kale \& Goh, 2014; Sundeen \& Sundeen, 2013; Wright \& Wilson, 2011).

Interview respondents from small and large districts alike were generally positive when asked about access to technology tools and resources. One respondent from a larger district and community mentioned, "We pretty much can use anything. I haven't really encountered anything that I would want to use that I haven't been able to use." Another respondent from a small school district and community shared, "The school and administration are very progressive, and there are grants that we apply for to help buy new technology gadgets...the school continually upgrades devices throughout the district."

Though they are positive as they discuss access, interview respondents also suggest some reasons why a lack of access to technology tools and resources could continue to be a barrier. Respondents from both small and large school districts and communities suggested that a lack of finances could affect access. One interview respondent from a large district and community shared her frustration, "No [technology access is not available] and the reason is because of funding to our district. I do not feel as though it is a school decision, I feel like that comes from the district." This same respondent later shared, "I am baffled on how such a large school district is so far behind when it comes to technology." Another respondent from a large district and community said, "Within budgetary restrictions they try their best to do what they can." Another respondent from a smaller district and community shared that she was unable to get the type of technology she desired because of a lack of finances, "They really like to cut corners price-wise, which is why I have a Promethean board and not a Smart board, I feel like they would if I ask for it, but I don't have administrator privileges."

The second research question in this study asks about other possible factors affecting barriers to technology use. Class size was one such factor for access to technology tools and resources in this study. Respondents within one category of smaller class sizes (16-20 students) indicated better access to technological tools and resources than those from a larger class size category (26-30 students). This finding makes sense, as teachers with fewer students may have more technology access for each student, bringing the ratio of devices to students closer to 1:1 (see Ruggiero \& Mong, 2015).

\section{Technology Training and Support}

The third most significant barrier reported in this study was the quality of technology training and support. This study found no significant differences between the reported quality of technology training and support between larger and smaller school districts and communities. Findings from the survey indicate that teachers tend to feel like they receive quality training and support to use technology, and they tend to be tolerant when the training may not be completely applicable.

Interview respondents, however, were mixed on this issue of quality training and support for technology integration. One respondent shared positive experiences with training and support, "They try to instruct us as best they can. We share ideas and there's a lot [to learn] at in-services." However, other interview respondents were not as positive when discussing the quality of tech- 
nology training. One respondent shared, "No, [training is not high quality] due to funding, positions have been cut, classes are minimal, who we have to train and come in and help is spread pretty thin." Another respondent also discussed, "We are encouraged to do it on our own through professional development rather than through the district."

Interview responses can provide insight in helping improve technology training and support. A respondent shared an alternative to formal professional development, "[I learn], not much from training, but from my peers. At [our] high school, teachers get together couple of times a week to talk about how to use different programs and share about each other's thoughts and ideas." These types of informal professional development experiences have been shown to increase teacher success at teaching and technology integration (see Jones \& Dexter, 2014; Kopcha, 2012).

\section{Administrative Support}

Issues related to administrative support comprise the second least significant barrier to technology use. Respondents reported high administrative support for the use of technology. Original findings from this study indicate that administrative support for technology use is higher in smaller school districts and communities than it is in larger school districts and communities.

Interview questions about administrative support also show that respondents feel like their administration overwhelmingly supports the use of technology for learning. One interview respondent shared, "Yes, the administration is progressive and all for advances in technology, they like activities where students are engaged and excited to learn." Another respondent shared how technology use is a part of her teaching evaluation, "when we have feedback on our drop-ins or formal observations that's definitely something they comment on and look for: the use of technology."

While all interview respondents felt that administrative support is high for technology integration, one comment from a respondent who works in a large school district discussed the issue of limited resources, "I believe my administration does support technology in the classrooms, but with limited resources, it makes it difficult to apply technology in the classroom." By contrast, no respondents from smaller districts and communities discussed the issue of limited resources. One respondent from a smaller district and community discussed the support he receives for technology integration, "any time I have a performance evaluation, they always comment on how they like my incorporation of technology. I don't think there are any obstacles in the way, and I have never run into any opposition."

\section{Beliefs about the Importance and Usefulness of Technology Tools and Resources}

The respondents within this study tend to have beliefs about technology consistent with high technology use. These include teacher beliefs that technology is useful for supporting learning, and that one is able to find and use technological resources successfully. Teacher beliefs about the importance and usefulness of technology tools and resources was the least significant barrier to technology use, and these beliefs were about the same in both larger and smaller school districts. This finding represents a change from earlier research on second-order barriers to technology use in which overcoming such barriers is suggested as an important focus (Ertmer, 1999; Ertmer \& Ottenbreit-Leftwich, 2010; Ertmer et al., 2012). Some possible reasons for this difference include that over time, teacher beliefs have changed, or that respondents in this study reported more positively about their own beliefs than is the reality.

Follow-up interview responses shared more information about teacher beliefs about the importance and usefulness of technology tools and resources. Respondents who were completely positive on the usefulness of technology tools and resources touted the multiple ways of reaching students, the engagement, and the possibility of physical activity offered by these tools and re- 
sources. Two respondents shared their thoughts about technology and engagement, "It is easier to draw students' attention and make the learning process fun," and "Students are more engaged when using technology and its devices or through hands on activities, the textbook is good as a resource but it doesn't engage the student the same as technology."

A more in-depth look into interview responses reveals that some respondents believed that certain conditions must be met before the use of technology tools and resources can support effective learning. These included having a specific purpose for using the tool or resource, using technology with the right kinds of lessons, and making sure students use the technology for its intended purpose.

Interview responses share more about what some teachers feel about technology integration. One respondent shared about lessons and technology, "Some lessons lend themselves more to being technology heavy, some are better if they are not." Respondents discussed how students may not use technology for its intended purpose, "Now that everything is online and tech-based cheating is much easier for them, they don't seem to be retaining the information as well as they have in previous years." Another respondent shared, "Some [students] are pretty engaged either way, others do poorly on the computer because they will do it half-butt and play games." One respondent shared a potential key to making sure learning and engagement happen during technologyintegrated learning, "If you are telling them to just go to a website and search around, they aren't going to get much out of it...it needs to be structured and there needs to be accountability."

Previous research on this topic shows that teachers must have beliefs consistent with technology use in order for successful technology integration to occur (Ertmer, 1999; Hew \& Brush, 2007). Overall, this study indicates that teacher beliefs on the usefulness and importance of technology tools may be adequate for effective technology integration.

\section{Limitations}

Limitations for this study include issues with the sample size and number of responses. The population of teachers within the state is close to the number of 12,161 total emails that were sent out, however, the researchers were able to obtain only 1,079 valid responses to the survey - a response rate of about $9 \%$. Appropriate statistical techniques were used to make inferences about the population based on the sample size.

Because the original survey in the first sending was blocked in some school districts, it is likely that faculty from these school districts were under-represented in the study. The researcher took care in sending out an alternative link that could be accessed by all respondents in two follow-up emails.

These survey findings on barriers must be interpreted with caution because of the self-report nature of the survey used in this study. Teachers may report more positively on their classroom practices than is the reality.

\section{Conclusion}

This study investigated barriers to technology integration in public K-12 classrooms in a rural North Midwestern state. Findings indicate that the most prevalent barrier to technology use among respondents is a lack of time to plan and prepare for technology integration, and that this barrier is more significant in smaller school districts and communities. Based on this finding, smaller school district administrators who wish to support the use of technology in teaching and learning should seek to allow teachers more time to plan and prepare for technology integration. However all teachers - whether from small or large districts - would likely benefit from having 
more time to plan and prepare for technology integrated lessons and activities. In addition, older teachers may need to be given more time for these types of planning activities.

The second most cited barrier was a lack of access to technology tools and resources. This was more of a barrier in larger, more suburban school districts. Administrators from larger school districts can seek to provide more and better access to technological tools and resources, especially within classrooms that have more students. This might include providing access to more and updated technology tools and allowing better access to online resources and activities.

As for training and support for technology use, new methods of professional development may help increase engagement and make professional development more relevant for teachers. These methods might include the informal meetings shared by an interview respondent, or social media connections that allow teachers to communicate and learn about their practice.

This study also showed that respondents tend to have beliefs consistent with high technology use, and they feel like they have quality administrative and training support for integrating technology. These overall findings suggest that efforts to develop positive beliefs about the importance and usefulness of technology (e.g., Holden \& Rada, 2011; Ruggiero \& Mong, 2015) may not be as important for populations of teachers similar to those in this study. However, it may also be that respondents have reported more highly of their own abilities and beliefs with technology than is the reality. If this is the case, efforts to increase teachers' ability to use and integrate technology may still be warranted.

Interview responses in this study provide a clearer picture of the reasons for barriers and also the feelings of teachers about barriers. Future research could be done to investigate further the barriers to technology integration in different types of classrooms, schools, and school districts in different states. Research can also focus on the specific reasons that barriers exist within these different settings, and on the feelings teachers have about these barriers.

\section{References}

An, Y., \& Reigeluth, C. (2012). Creating technology-enhanced, learner-centered classrooms: K-12 teachers' beliefs, perceptions, barriers, and support needs. Journal of Digital Learning in Teacher Education, 28(2), 54-62.

Bauer, J., \& Kenton, J. (2005). Toward technology integration in the schools: Why it isn't happening. Journal of Technology and Teacher Education, 13(4), 519-546.

Clark, K. (2006). Practices for the use of technology in high schools: A delphi study. Journal of Technology and Teacher Education, 14(3), 481-499.

Creswell, J. W. (2006). Qualitative inquiry and research design: Choosing among five approaches (2nd ed.). Thousand Oaks, CA: Sage Publications.

Cuban, L. (2009). Oversold and underused: Computers in the classroom. Cambridge, MA: Harvard University Press.

Dawson, V. (2008). Use of information communication technology by early career science teachers in Western Australia. International Journal of Science Education, 30(2), 203-219.

Ertmer, P. A. (1999). Addressing first-and second-order barriers to change: Strategies for technology integration. Educational Technology Research and Development, 47(4), 47-61.

Ertmer, P. A., \& Ottenbreit-Leftwich, A. T. (2010). Teacher technology change. Journal of Research on Technology in Education, 42(3), 255-284.

Ertmer, P. A., Ottenbreit-Leftwich, A. T., Sadik, O., Sendurur, E., \& Sendurur, P. (2012). Teacher beliefs and technology integration practices: A critical relationship. Computers \& Education, 59(2), 423-435. 
Hew, K. F., \& Brush, T. (2007). Integrating technology into K-12 teaching and learning: Current knowledge gaps and recommendations for future research. Educational Technology Research and Development, 55(3), 223-252.

Holden, H., \& Rada, R. (2011). Understanding the influence of perceived usability and technology selfefficacy on teachers' technology acceptance. Journal of Research on Technology in Education, 43(4), 343-367.

Howley, A., Wood, L., \& Hough, B. (2011). Rural elementary school teachers' technology integration. Journal of Research in Rural Education, 26(9), 1-13.

Inan, F. A., \& Lowther, D. L. (2010). Factors affecting technology integration in K-12 classrooms: A path model. Educational Technology Research and Development, 58(2), 137-154.

Jones, W. M., \& Dexter, S. (2014). How teachers learn: The roles of formal, informal, and independent learning. Educational Technology Research and Development, 62(3), 367-384.

Kale, U., \& Goh, D. (2014). Teaching style, ICT experience and teachers' attitudes toward teaching with web 2.0. Education and Information Technologies, 19(1), 41-60.

Kopcha, T. J. (2012). Teachers' perceptions of the barriers to technology integration and practices with technology under situated professional development. Computers \& Education, 59(4), 1109-1121.

Lewis, J. A. (2010). Improving rural k-12 teachers' use of technology for instruction and student learning (Unpublished doctoral dissertation). Walden University, Minneapolis, MN.

Lyons, T. (2007). The professional development, resource and support needs of rural and urban ICT teachers. Australian Educational Computing, 22(2), 22-31.

Mills, G. E., \& Gay, L. R. (2016). Educational research: Competencies for analysis and applications. Boston, MA: Pearson

O’Bannon, B. W., \& Thomas, K. (2014). Teacher perceptions of using mobile phones in the classroom: Age matters! Computers \& Education, 74, 15-25. http://doi.org/10.1016/j.compedu.2014.01.006

Reigeluth, C. M., Beatty, B., \& Myers, R. (2016). The learner-centered paradigm of instruction. In C. M. Reigeluth, B. Beatty, \& R. Myers (Eds.), Instructional-design theories and models: The learnercentered paradigm of education. New York, NY: Routledge.

Reigeluth, C. M., \& Karnopp, J. R. (2013). Reinventing schools: It's time to break the mold. Lanham, MD: Rowman \& Littlefield Education.

Reinhart, J. M., Thomas, E., \& Toriskie, J. M. (2011). K-12 teachers: Technology use and the second level digital divide. Journal of Instructional Psychology, 38(3), 181-193.

Ritzhaupt, A. D., Dawson, K., \& Cavanaugh, C. (2012). An investigation of factors influencing student use of technology in K-12 classrooms using path analysis. Journal of Educational Computing Research, 46(3), 229-254.

Ruggiero, D., \& Mong, C. J. (2015). The teacher technology integration experience: Practice and reflection in the classroom. Journal of Information Technology Education: Research, 14, 161-178. Retrieved from http://www.informingscience.org/Publications/2227

Sang, G., Valcke, M., Braak, J. van, \& Tondeur, J. (2010). Student teachers' thinking processes and ICT integration: Predictors of prospective teaching behaviors with educational technology. Computers \& Education, 54(1), 103-112.

Sundeen, T. H., \& Sundeen, D. M. (2013). Instructional technology for rural schools: Access and acquisition. Rural Special Education Quarterly, 32(2), 8-14.

Wright, V. H., \& Wilson, E. K. (2011). Teachers' use of technology: Lessons learned from the teacher education program to the classroom. SRATE Journal, 20(2), 48-60. 


\section{Biography}

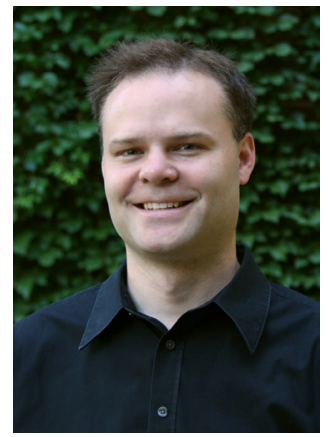

Dr. Gregory M. Francom is an assistant professor of E-Learning at Northern State University in Aberdeen, South Dakota. He prepares preservice teachers to successfully use educational technologies for learning. Dr. Francom has researched and implemented various task-centered, project-based, and constructionist learning experiences for K-12 and higher education students. He is the author of the first ever multiplatform interactive digital textbook on educational technology, Educational Technology for Teachers, and is currently studying methods for and factors affecting educational technology use among teachers. 